\title{
Civilisations
}

Revue internationale d'anthropologie et de sciences

humaines

44 | 1997

Les peuples des forêts tropicales

\section{Introduction régionale}

Françoise Aubaile-Sallenave

URL : http://journals.openedition.org/civilisations/1626

DOI : 10.4000/civilisations. 1626

ISSN : 2032-0442

\section{Éditeur}

Institut de sociologie de l'Université Libre de Bruxelles

\section{Édition imprimée}

Date de publication : 1 janvier 1997

Pagination : 170-175

ISBN : 2-87263-122-4

ISSN : 0009-8140

\section{Référence électronique}

Françoise Aubaile-Sallenave, «Introduction régionale », Civilisations [En ligne], 44 | 1997, mis en ligne le 29 juin 2009, consulté le 01 mai 2019. URL : http://journals.openedition.org/civilisations/1626 ; DOI : 10.4000/civilisations. 1626

\section{(c) Tous droits réservés}




\section{- INTROOUCTION RÉGIIONHLE}

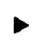

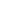

Françoise AUballe-SALLENAVE 
La forêt tropicale humide couvrait jusqu'à la fin du XIX' siècle la majeure partie de l'Asie du Sud-Est. Ce sont des régions hautement montatgneuses et soumises à la mousson. Elles se situent sur la partie continentale (Thailande, Laos, Cambodge, Viêtnam) et sur les très nombreuses îles et presqu'îles bordées par les océans Indien et Pacifique (La Malaisie : péninsule malaise et Boméo; l'Indonésie : Java, Sumatra, les Moluques, les Célèbes, Irian Jaya; auxquelles s'ajoutent les Philippines et la Papua New-Guinie).

Dans ces pays longtemps colonisés, les frontières politiques ne correspondent pas aux frontières géographiques : la Malaisie comprend outre la péninsule malaise, le Sabah et Sarawak, deux États au nord de Bornéo. L'Indonésie comprend, outre les très nombreuses petites îles, Sumatra, Java, les Célèbes, les Moluques et l'Irian Jaya qui forme la moitié occidentale de Nouvelle-Guinée et Kalimantan situé au nord de Boméo.

Les Malais, une ethnie dominante, islamisée depuis plusieurs siècles, ont peuplé et colonisé, depuis les premiers siècles de l'ère chrétienne, l'ensemble de la péninsule malaise ainsi que l'archipel indonésien en repoussant vers l'intérieur les populations préexistentes.

L'histoire économique et sociale a déterminé la grande diversification des peuplements et des langues qui résulte des migrations à diverses époques dans les diverses régions, avec deux extrêmes :

D'une part, la péninsule malaise qui compte 70.000 Orang Asli (ainsi appelle-t-on les Aborigènes; ils représentent $0,5 \%$ de la population totale), dont $5 \%$ seulement sont encore chasseurscollecteurs. Les Orang Asli sont divisés en 19 tri- bus qui vivent dans l'intérieur montagneux dont sept regroupent moins de 800 personnes et deux ont plus de 20.000 membres. Ils sont presque tous assimilés à des degrés divers.

$\grave{\Lambda}$ l'opposé, la Nouvelle-Guinée (Irian Jaya et Papua New-Guinie) compte plus de 1.000 .000 de forestiers qui représentent plus de 800 ethnies, soit $18,5 \%$ de la population totale. L'effectif de ces groupes est très faible : $85 \%$ comptent moins de 5.000 membres, $1 \%$ seulement dépasse 20.000 personnes. Cette île, la dermière entrée en contact avec le monde, contient la plus grande densité d'ethnies et de langues (avec la Nouvelle-Calédonie) au monde.

La situation dans les autres pays n'est pas plus simple. Rappelons cependant qu'à l'inverse des actions menées par certaines organisations, il ne faut pas se focaliser sur une seule ethnie, comme cela été fait pour les Penan. Ies problèmes sont plus complexes et doivent s'envisager de façon plus globale.

Ainsi, à Bornéo, où l'on a souligné avec raison la situation difficile des Penan, il faut rappeler que 350 Penan seulement sont nomades et chasseurs-collecteurs alors que 2.000 sont sédentaires et agriculteurs sur brûlis. Par contre, la totalité des populations forestières représente 950.000 personnes réparties en 62 ethnies dont 12 ont moins de 500 membres et deux seulement comptent plus de 100.000 personnes.

La situation aux Philippines est semblable, où l'on compte au moins 52 ethnies forestières totalisant environ 1.580 .000 personnes dont trois ethmies de moins de 500 personnes. À ces forestiers, s'ajoutent les grands riziculteurs qui pratiquent aussi l'agriculture sur brûlis. 
Les îles d'Indonésie (Sumatra, Mentawai, Sulawasi, Moluques, Ceram), quant à elles, comptent 94 ethnies forestières totalisant 4.780.000 personnes dont le plus petit groupe est de 300 personnes (les Akit de Sumatra) et le plus important de 1.500 .000 (les Kampung, essarteurs de Sumatra).

\begin{tabular}{lrrr} 
& $\begin{array}{r}\text { Ethnies } \\
\text { forestières }\end{array}$ & population & $\begin{array}{r}\% \text { pop. } \\
\text { totale }\end{array}$ \\
\hline Bornéo & 62 & 950.000 & 7,6 \\
Nouvelle-Guinée & 806 & 1.000 .000 & 18,5 \\
Philippines & 52 & 1.600 .000 & 2,6 \\
Péninsule malaise & 16 & 100.000 & 0,9 \\
Indonésie & 94 & 4.800 .000 & 2,8
\end{tabular}

Ces régions sont englobées depuis très longtemps (quatre ou cinq siècles av. J.-C.) dans des circuits commerciaux monétarisés (on a retrouvé des monnaies romaines en Indochine) qui touchaient à divers niveaux toutes les sociétés.

Ainsi, les Penan, qui sont l'archétype des chasseurs-collecteurs, payent leur dot en gongs chinois de bronze des XIJe et XIII ${ }^{2}$ siècles, qu'ils stockent dans des cavernes, ainsi qu'avec de grandes jarres chinoises en céramique des XVe et $\mathrm{XVI}^{\mathrm{e}}$ siècles gardées dans les maisons-longues.

Qu'allaient chercher ces commerçants indiens, malais, chinois, persans, arabes, puis, à partir du XVI ${ }^{\mathrm{e}}$ siècle, portugais, espagnols, hollandais, français, anglais? Ce sont les fameuses épices et parfums : camphre de Bornéo, benjoin de Sumatra (que les Arabes appelaient jâwî, «de Java», comme ils appelaient cette île), bois d'aloès de Malaisie et du Cambodge, muscade et clou de girofle des Moluques, zédoaire et diverses zingibé- racées; sans oublier les produits animaux : bezoar, bec de calao, corne de rhinocéros (recherchée pour la médecine chinoise jusqu'à extinction de cet animal).

Et pourtant l'impact de cet immense commerce de produits de cueillette et de culture qui a duréplus de 20 siècles est quasiment nul sur le couvert forestier:

Ces hommes ont, par contre, apporté de nouvelles religions : bouddhisme aux premiers siècles de l'ère chrétienne, puis l'islam à partir du Xe siècle environ, enfin le christianisme à partir du $\mathrm{XVI}{ }^{\mathrm{e}}$ siècle, notamment aux Philippines. Ces nouvelles religions s'opposèrent et s'opposent toujours fortement aux croyances des populations préexistentes où le chamanisme prédomine. Cependant, en général, les différentes colonisations sont restées sur les bords de ces îles, laissant les populations de l'intérieur en dehors de leur sphère d'influence.

\section{LR DEMANDE DE L'OCCLDENT}

Jusqu'au début du XXe siècle, l'intérêt pour ces pays n'a concerné que des produits de cueillette. Ce n'est qu'à partir du XIX siècle, et surtout au XXe siècle, que s'accroit la demande des pays occidentaux en bois tropicaux et certains produits industriels, laque, damar, caoutchouc.

C'est aussi à ce moment-là que l'on assiste à la création de grandes plantations de tecks et d'hévéas à Java, dans la péninsule malaise et le sud-Viêtnam.

Après la seconde guerre mondiale, l'accélération de la demande en bois d'ébénisterie et en rotins (produit de cueillette en Malaisie et à Sumatra) s'amplifie. Apparaissent à ce moment-là les 
demandes en bois de papeterie : cette dernière production a des conséquences beaucoup plus graves, car elle utilise les bois de toutes tailles et permet une déforestation «à blanc», un découvert du tissu végétal ce qui entrâne inondations, glissements de terrains, stérilisation par dépot de latérite, sans parler de la spoliation pour les populations forestières de leur ravitaillement de première nécessité fourni par la chasse et la cueillette.

On ne peut s'empêcher de citer deux chiffres tristement éloquents : la grande forêt couvrait, en 1950, 65\% de la surface totale des Philippines; en 1992 , elle ne couvre plus que $22 \%$ de la surface totale de cet archipel. En 40 ans les exploitants occidentaux américains et japonais ont détruit des forêts que des populations vivant d'essartage et de cultures sur brûlis ont maintenu pendant des millénaires.

Après l'indépendance en 1961, le gouvernement malais a mis sur pied de vastes programmes qui, tout en sédentarisant et assimilant peu à peu les Orang Asli, lui a permis de développer largement, sur de petites surfaces, les cultures de rente de palmiers à huile et d'hévéas dans la péninsule malaise. Cela s'est aussi produit à Sumatra.

\section{L'AGROFORESTEAIE}

Ces types occidentaux de monoculture s'opposent à une très ancienne forme d'agriculture arlborée que les chercheurs européens découvrent et commencent à connaître et à décrire. Cette arboriculture, à Sumatra, Java et en Malaisie, sous une forme très achevée, consiste à mêler des cultures vivrières à des cultures à long terme d'arbres utiles de sorte que de vieilles forêts qui paraissent naturelles à nos yeux d' $O$ ccidentaux, s'avèrent en réa- lité plantées par l'homme. Ce type d'agriculture reste malheureusement méprisé par les pouvoirs publics sous l'influence occidentale, alors qu'elle est un exemple et un modele de foresterie tropicale dénommée par les Occidentaux «Agroforesterie».

\section{LE SUSTÈME JUPIDIOUE DE CES SOCIËTÉS}

En fait, en ce qui concerne la propriété de la terre, les juridictions d'État ne font que prolonger celles mises en place par les colonisateurs anglais en Malaisie et hollandais en Indonésie. C'est-àdire que ce sont des systèmes qui sont basés sur les concepts juridiques occidentaux, concepts qui ne tiennent pas compte du droit coutumier de l'adat (terme arahe) qui règle les structures du pouvoir des communautés traditionnelles et qui, dans certains cas, conçoit la propriété collective et l'usufruit de la terre. Par ailleurs l'accès à la citoyenneté est-il lié à l'adoption de la religion dominante, l'islam. Ceci est explicite dans la Constitution malaise et sous-entendu dans la Constitution indonésienne.

\section{LES DEPPACECEENTS QE POPULATIONS}

À l'exploitation intensive des forêts, des mines, la création de barrages gigantesques, s'ajoutent les problèmes de déplacements et de déstructuration des populations.

La guerrilla communiste a entraîné des mouvements, de très fortes pressions et des destructions de populations forestières en Malaisie, aux Philippines ${ }^{[1]}$.

D'autre part, la très forte disparité dans les densités de populations entre certaines îles a poussé à des déplacements programmés. Ce fut ce que l'on a appelé en Europe la «transmigration". 
Le déplacement forcé de familles javanaises n'a pas toujours réussi et le mouvement est, pour l'instant, légèrement en régression. Cependant les risques peuvent s'accentuer; à Almahera, où la forêt couvre, en 1990, 79\% de la surface totale, le gouvernement indonésien projette des transmigrations associées à une mise en place de cultures de rente. C'est ce que font aussi les Malais au Sabah et à Sarawak.

Par contre, les migrations spontanées, qui sont surtout le fait de populations côtières allant vers l'intérieur, ne sont pas contrôlées et sont beaucoup plus dangerenses pour les populations forestières et leur milieu. C'est le cas aux Moluques (en particulier à Séram comme l'a étudié Roy Ellen), mais aussi au Viêtnam et celui des Bugis aux Philippines. Non seulement, ces populations côtières prennent leur territoire, leurs terres et leurs ressources aux forestiers, mais ils détruisent leur milieu car ils ne savent pas "gérer" la culture sur brûlis.

En outre, l'état de guerrilla communiste a entrâné pendant longtemps des mouvements de populations en Malaisie et aux Philippines déstabilisant les tribus de l'intérieur et permettant aux forces armées du gouvernement de pénétrer et de les détruire sous prétexte de collusion avec les communistes.

\section{QUI PARTIOUE LA CULTURE SUR BAÎLLS?}

Il faut souligner l'importance de la forêt non seulement pour les chasseurs-collecteurs et les agriculteurs sur brûlis, mais aussi pour les grands riziculteurs qui pratiquent tous l'essartage en complément du riz des terrasses irriguées, pour pallier les mauvaises récoltes des terres inondées. Par ailleurs, la conservation des forêts de crête assure la régularité des cours d'eau nécessaire à leur agriculture inondée. Deux exemples l'illustrent: celui des Ifugao aux Philippines, très précisément étudiés par Harold Conklin:

la division des terres chez les Ifugan de Luzon, Philippines, montre l'importance de l'essart et des territoires nécessaires pour l'essart (territoire de Bontoc) : les essarts occupent $6 \%$ du territoire de cette population, les terrasses irriguées 15 à 20\%, les vergers 30 à $35 \%$, les prairies de roseaux $35 \%$ (pour l'essartt) et les forêts communales 10 à $25 \%$.

Les Minang Kabau, de Sumatra, en Indonésie (2.500.000), qui sont une grande ethnie de riziculteurs de riz irrigué, pratiquent également la culture sur brûlis du riz de montagne à laquelle ils associent des parcelles de jardins ${ }^{[?]}$.

\section{LA SITUATIOH ET LES PROBLÈMES}

Ies Philippines sont dans une situation désespérée qu'il ne faut pas aggraver. Reprenons un chiffre éloquent : la surface de la forêt est passée de $62 \%$ en 1950 à $22 \%$ en 1992 faisant disparaitre le mode de vie de nombreuses populations notamment à Negros, nord-Luzon, Samar et Mindanao. Dans cet archipel, comme ailleurs, la surexploitation forestière a deux conséquences majeures: ce sont les glissements de terrains et les inondations qui ont provoqué des catastrophes humaines dans la péninsule malaise, aux Philippines et menacent plusieurs vallées, à Bornéo. Autre point noir, ce sont les migrations des populations de la côte vers l'intérieur pour occuper les terres des populations forestières, asservir ces populations et appauvrir définitivement les terres.

Dans le domaine des ressources alimentaires, les sagoutiers sauvages et cultivés (Eugeissona spp 
et Metroxylon spp), foumissent le féculent de base de la majeure partie des populations de Bornéo, de Nouvelle-Guinée, des Célèhes, des Moluques. Ces palmiers croissent dans les forêts marécageuses et dans celles allant jusqu'à $1.000 \mathrm{~m}$ d'altitude; ce sont précisément ces forêts d'un accès facile qui sont les plus exploitées, avec des conséquences dramatiques pour les populations.

la situation à Boméo est également préoccupante; à Sarawak, les problèmes majeurs viennent, outre la surexploitation des forêts, de la création, réalisée ou en projet, de barrages gigantesques, auxquels les populations (Penan, Kayan Kenyah, Kelabit) résistent sous forme de «barricades».

À Kalimantan, à l'exploitation forestière s'ajoute le traumatisme que constitue la politique de peuplement dite «Transmigration».

Dans la péninsule malaise, les populations Orang $A$ sli (peu nombreuses) sont en voie d'assimilation et subissent de fortes pressions du gouvennement pour l'arrêt des cultures sur brûlis, la sédentarisation et l'engagement comme ouvriers agricoles dans le système des cultures de rente. Assimilation signifie aussi islamisation pour ces populations en général animistes.

Cependant, en novembre 1991, des glissements de terrains provoqués par la déforestation massive en moyenne altitude ont, semble-t-il, entrâné une certaine prise de conscience de la nécessité qu'il y avait d'avoir une politique forestière; ce qui a entre autres, stoppé l'exploitation dans certaines zones. Sachant cela, il faudrait accentuer la sensibilisation des pouvoirs publics à la situation. Dans le cas des Orang Asli, la déforestation, plus que l'englobement dans les cultures de rentes, affecte leur mode de vie car elle réduit fortement l'accès aux ressources traditionnelles.

En conclusion, les Philippines sont un cas exemplaire de destruction drastique et rapide d'écosystèmes abritant de nombreuses populations; Bornéo et l'Irian Jaya restent des points très chauds et, dans une moindre mesure, dans l'immédiat, les colonies orientales de l'Indonésie, Moluques et Sulawasi.

Les atteintes sur ces populations bouleversent leur ordre économique, social, mental, religieux.... on impose la langue de l'ethnie dominante, on impose une religion, l'islam, on inpose une économie qui bouleverse l'économie traditionnelle, on impose une société qui ignore la propriété collective des terres, on impose une situation de guerre, on bouleverse le milieu naturel et l'on détruit les ressources nécessaires à la vie. Voilà ce qu'a apporté la société occidentale et ses émules.

\section{NOTES}

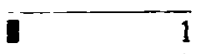

La répression américaine au Viêtnam ct les moyens employés pour détruire le milieu forestier par des défoliants (cf. Condominas, ce volume) laissent des régions entières exsangues et stériles 20 ans après.
Dans la culture sur brîlis, la coupe des arbres est particille, c'est-à-dire que l'on ne dessouclie pas, de sorte qu'apres une exploitation de 2 à 3 ans, les arhres repoussent at an bout de 20 à 25 ans ils ont à nouveau atteint

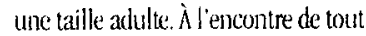
a que disent les forestiers occidentaux et a leur suite les gouvemements, lion peut conclure que la culture sur brîlis mainlionl l'écosystème de la fortêt. Lessart semble ctre un défrichement total du terrain avec dessouch age ce gui empeche la repousse des arbres; c'est ce qui s'est paissé lors des grandes défriches ordomancées par les monastères d'aurope occidentale, au Moyen Age. 